\title{
Study on Assays for the Detection of Serum Antibodies to Measles from Children and Its Standardization
}

\section{Kei Numazaki}

Division of International Infectious Diseases, Graduate School and Departments of Pediatrics, University Hospital, International University of Health and Welfare, Nasu-shiobara, Tochigi, 329-2763, Japan

\begin{abstract}
Background: Measles is an acute febrile rashes and infections caused by the measles virus belonging to the paramyxovirus. Traditionally the diagnosis of measles had been based on clinical symptoms in daily clinical practice. In recent years, many clinical cases do not show typical clinical manifestations and laboratory confirmation of the disease is definitely required. The aim of this study is to investigate the possibility of establishment of serological assays for diagnosis of measles in the pediatric field with universal standard.

Methods: Serum samples were obtained from the 79 patients in the pediatric field. The correlation of the results between obtained by the diagnostic serological assays such as HI, NT, PA and EIA, and laboratory diagnosis and clinical findings or symptoms in general pediatric populations was investigated.

Results: We examined the correlation of sensitivity and specificity between serological assays and symptoms in patients with measles. PA showed lower sensitivity and specificity than EIA. Antibody titers obtained by PA assay were higher compared to conventional HI method. The serum prevalence by PA was $98.7 \%, 97.5 \%$ by EIA and 86.1 by HI. HI test comparing with NT the sensitivity and specificity was low. In high PA antibody serum of acute phase of infection meaningful correlation was observed with NT antibody titers.

Conclusion: Measles diagnosed with clinical findings should be identified with differential diagnosis of measles cases obtained by laboratory confirmation. Although NT test assumed to reflect the immunity against infectious agents, each method of $\mathrm{HI}$ and not only the problems on sensitivity and specificity, but also interventions on issues became alert. International standardization and universalism seems to be necessary for EIA assays.
\end{abstract}

\section{Introduction}

Measles is a viral infectious disease caused by the measles virus, an enveloped negative-strand RNA virus of the Morbillivirus genus in the Paramyxoviridae. There is no specific treatment for measles and most pediatric patients recover within 2-3 weeks. However, particularly in malnourished children and infants with lowered immunity; measles can cause serious complications, including blindness, encephalitis, severe diarrhea, ear infection and pneumonia. Measles was estimated to infect 20 million people per year worldwide, and to result in 242,000 deaths [1,2]. Although so-called Koplik's spots are known as typical symptoms of measles, a typical clinical case often shows no symptoms and that makes early diagnosis quite difficult $[3,4]$.

Since atypical cases of measles are not uncommon, diagnosis based on laboratory testing is required $[5,6]$. Laboratory diagnosis by serum IgM antibody-detection, RT-PCR assay, and viral isolation are now established for the confirmation of the diagnosis of measles infection [7]. Because of high sensitivity and specificity, these methods are the most reliable for laboratory diagnosis of Measles. However, although they are effective for epidemiological investigation, they are not suitable for use in daily clinical practice [8]. Not from the importance of rapid diagnosis, the serological diagnosis of measles has been reemphasized to establish the daily application in general pediatric clinics [9]. We already reported about the fundamental results of rapid diagnostic reagent for measles, this time we will report about the diagnostic significance of serological assays $[10,11]$.

For the definitive diagnosis of measles the importance of laboratory procedures have highlighted to significant rise of serum IgG antibodies in confirmed acute and convalescent paired sera, viral isolation, genomic detection and detection of specific serum IgM antibody. Practical assays for detection serum antibodies include hemagglutination-inhibition (HI) test, serum neutralization test (NT), gelatin particle agglutination (PA) and enzyme immunoassay (EIA) [12]. However, there are still problems to be solved for establishment and universal standardization of these assays for children [13].

As measles virus antibody tests for the diagnosis of measles and the rapid clinical decision, traditionally HI test has been employed. But use blood cells get year after year becomes difficult or because the assay was developed as an alternative to conventional method. Normal serum before vaccination seems to be this time, using various antibody measurement and comparison of antibody titers, studied the usefulness of PA. Opportunities of the booster effect because, in addition to that on the other hand, widespread use of measles vaccine in young people is the most vaccine reduced measles incidence of less the decline in antibody levels of concern.

The aim of this study is to investigate the possibility of establishment of serological assays for diagnosis of measles with universal standard. Samples near the limit of detection sensitivity considering correlation of differences of methods were investigated.

\section{Materials and Methods}

During the time of March 2008 to July 2010 clinical samples were "Corresponding Author: Dr. Kei Numazaki, Division of International Infectious Diseases, Graduate School and Departments of Pediatrics, University Hospital, International University of Health and Welfare, Nasu-shiobara, Tochigi, 329-2763, Japan; E-mail: rdelrio@hsjdbcn.org

Citation: Numazaki K (2015) Study on Assays for the Detection of Serum Antibodies to Measles from Children and Its Standardization. Int J Pediatr Neonat Care 1: 108. doi: http://dx.doi.org/10.15344/2455-2364/2015/108

Copyright: @ 2015 Numazaki. This is an open-access article distributed under the terms of the Creative Commons Attribution License, which permits unrestricted use, distribution, and reproduction in any medium, provided the original author and source are credited. 
Citation: Numazaki K (2015) Study on Assays for the Detection of Serum Antibodies to Measles from Children and Its Standardization. Int J Pediatr Neonat Care 1: 108. doi: http://dx.doi.org/10.15344/ijpnc/2015/108

Page 2 of 4

obtained from the 79 patients in the pediatric field ( 0 to 15 years of age; average 8.1 years, 41 males, 38 female) with suspected measles infection at 14 medical facilities in the area of Tokyo, Chiba, Osaka and Hokkaido of Japan. In the collaboration facilities, serum specimens of patients were collected. Using serum antibody measurement conducted. Specimen collection was done by the physicians' responsibilities under the agreement based on ethical guidelines on clinical research (issued by the Ministry of Education and Science and the Ministry of Health, Welfare and Labor of Japan) and the Helsinki Declaration (World Medical Association). Serum was separated from other blood components and kept refrigerated at $4^{\circ} \mathrm{C}$ until testing. Using these serum specimens, HI, EIA and PA assays were performed by comparison.

NT test was performed in 29 samples of measles virus antibody titers of $1: 8$ to $1: 256$ (by conventional HI test). Also, on the same specimen others have conducted method on EIA (IgM, IgG) and PA. HI tests were performed due to ordinary laboratory standard and pathogen detection manual by National Institute of infectious diseases (NIID), Japan. Commercially available EIA (Denka Seiken and Co. Ltd.) and PA (Fujirebio Inc) kits were used to detect serum antibodies against measles $[14,15,16]$. Serum samples were also collected to detect measure-specific IgM antibodies. For NT tests by the plaque reduction and cytopathic (CPE) suppression method were performed using measles virus of Edmonston and different wild genotypes on Vero/hSLAM cells. Sensitivity and specificity between assays, HI, NT, EIA (IgM, IgG), PA were compared each other. Vero cells were transfected to express human SLAM signaling lymphocyte activation molecule CDw150 as Vero/hSLAM [17].

All study procedures were approved by the Research Ethics Committee of International University of Health and Welfare, Tochigi, Japan.

\section{Results}

We examined the correlation of sensitivity and specificity between serological assays (Figures 1-3) and symptoms in patients with measles. PA showed lower sensitivity and specificity than EIA. Antibody titers obtained by PA assay were higher compared to conventional HI method. The serum prevalence by PA was $98.7 \%$, $97.5 \%$ by EIA and 86.1 by HI. Positive correlation with the IgG (EIA) low trend, the most results by HI showed less than $1: 8$, and even IgG (EIA) at 41.4 (EIA index) specimen was less than 1:8 by HI method. Also in IgG (EIA)-negative but IgM (EIA)-positive samples, HI titers were less than 1:8 (data not shown).

NT method using plaque reduction in Vero/hSLAM cell had enough repeatability and objectivity compared with methods based on traditional CPE method. Some samples high EIA titer showed negative results by HI. HI test comparing with NT the sensitivity and specificity was low (Figure 4). In high PA antibody serum of acute phase of infection meaningful correlation was observed with NT antibody titers (Figure 5).

Serum IgM antibodies against measles were detected in some patients, Koplik's spots were pointed out in patients who showed no rashes. Measles D5 strain was identified from most specimens. Two patients without rash had not appeared in the relationship between clinical symptoms and positive matches, obtained a positive decision. In what had been diagnosed with measles in clinical findings so far Koplik's spots, judged measles diagnosis differential diagnosis difficult clinical symptoms alone was serological negative results.

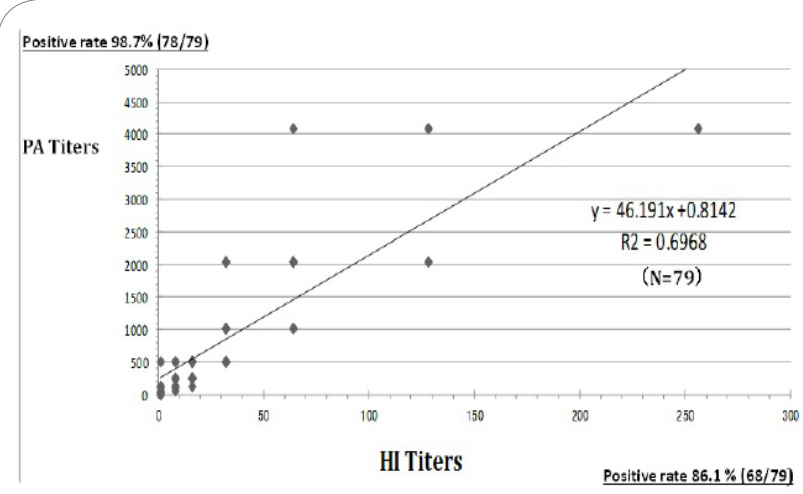

Figure 1: Correlation of measles antibody titers by $\mathrm{HI}$ and PA assays.

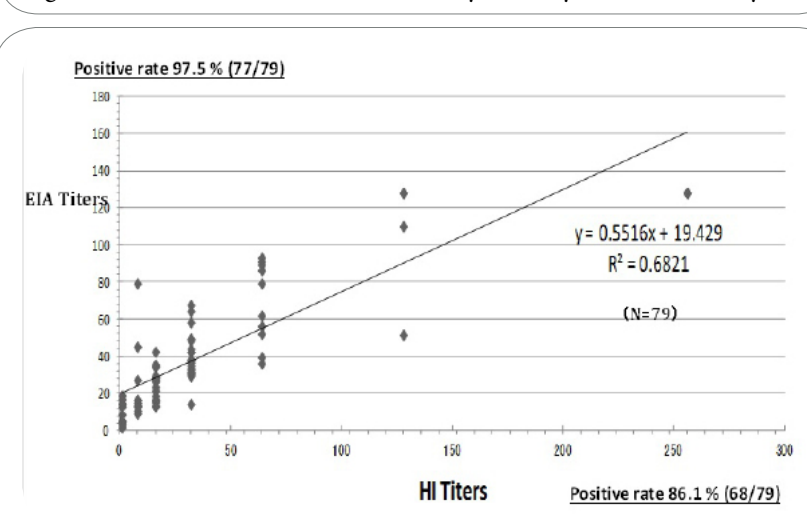

Figure 2: Correlation of Measles Antibody Titers by HI and IgG EIA assays.

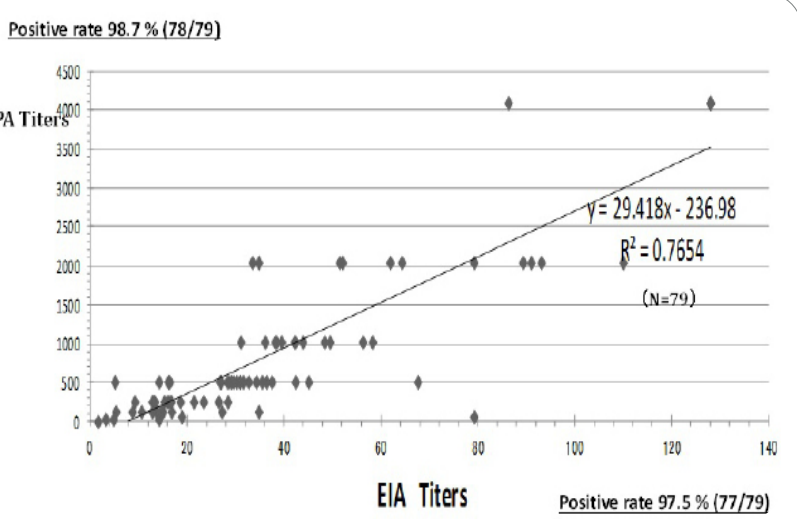

Figure 3: Correlation of Measles Antibody Titers by HI and IgG EIA assays.

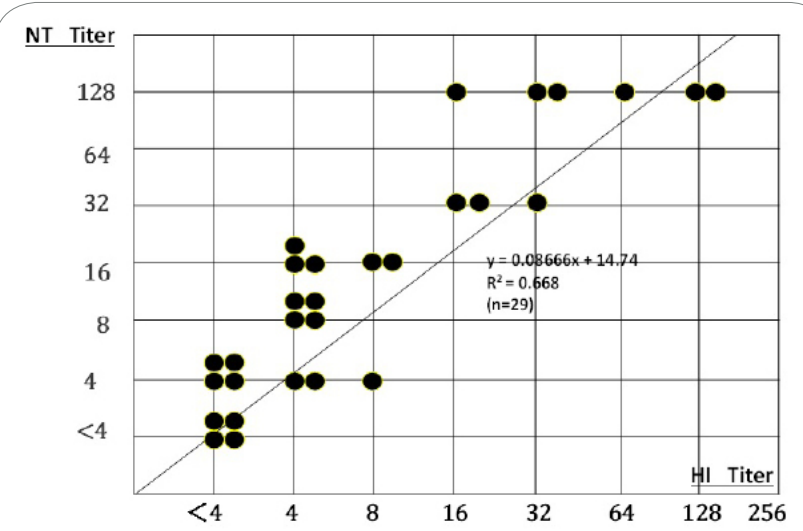

Figure 4: Correlation of Measles Antibody Titers by NT and HI assays. 
Citation: Numazaki K (2015) Study on Assays for the Detection of Serum Antibodies to Measles from Children and Its Standardization. Int J Pediatr Neonat Care 1: 108. doi: http://dx.doi.org/10.15344/ijpnc/2015/108

Page 3 of 4

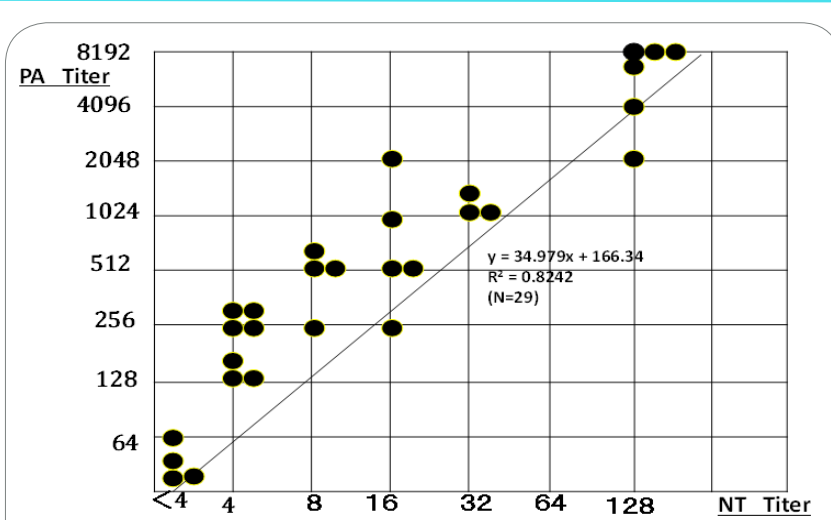

Figure 5: Correlation of Measles Antibody Titers by NT and PA assays.

\section{Discussion}

Measles is still globally prevalent focusing on developing countries every year and 452,000 person death cases (lethality $3 \sim 5 \%$ ) are estimated to have occurred [2]. WHO is formulated global measles elimination measures strategic planning for mortality reduction and regional elimination. While many countries conducted a thorough vaccination and surveillance, almost close to the eradication of achieving in the part already to Americas, Europe, and South Africa and Middle East countries. Realization of the measles eradication, including Japan WHO Western Pacific (WPRO) is the region most of the measures was delayed and even adopted the draft had not set conditions, currently targeting 2012 prima facie achievement [1].

Although the number of measles patients in Japan has declined once more still 1 year $\sim 500$ people are estimated. In respect of the measures protecting overall public health from high severity in pediatric, adult onset even in question, measles is the key $[5,6]$. The measles elimination important in strengthening surveillance and vaccination rates of improvement. Also enhancing epidemiological surveillance and scientific monitoring system based on the characteristics of virus and gene is essential for the eradication of measles.

Establishment of effective measures against the spread of the epidemicinfection is required along with prevention by vaccination in measles. Atypical cases especially after the measles vaccine inoculation of secondary immunodeficiency, pointed out experiments laboratory diagnostic importance [3-5]. Currently, traditional clinical diagnosis depending on symptomatic findings often leads to misdiagnosis of measles. Establishment of serological assays for measles is important not only from the standpoint of the prevention of infection, but also confirms the definitive diagnosis [18].

Construction of surveillance system based on laboratory positive proof of measles control measures at the global level is indispensable. The inspection in our country based on the census report is also required. Although NT test assumed to reflect the immunity against infectious agents, at present processing of number of specimen is in a difficult situation. In each method of HI, CF, PA not only the problems on sensitivity and specificity, but also interventions on issues became alert. International standardization and universalism seems to be necessary for EIA assays. Considered required further diagnosis standardization and quality control.

\section{Conclusion}

Measles diagnosed with clinical findings should be identified with differential diagnosis of measles cases obtained by laboratory confirmation. Although NT test assumed to reflect the immunity against infectious agents, each method of HI and PA not only the problems on sensitivity and specificity, but also interventions on issues became alert. International standardization and universalism seems to be necessary for EIA assays.

\section{Competing Interests}

The authors have declared that no competing interests exist.

\section{Acknowledgments}

The author expresses thanks to Yoshiyuki Mochida and Mika Satodate, Denka Seiken Co. Ltd., Tokyo, Japan, for their valuable technical assistance.

\section{References}

1. Numazaki K (2007) Current problems of measles control in Japan and Western Pacific Region. Vaccine 25: 3101-3104.

2. Centers for Disease Control and Prevention (CDC) (2007) Progress in global measles control and mortality reduction, 2000-2006. MMWR Morb Mortal Wkly Rep 56: 1237-1241.

3. Paunio M, Peltola H, Valle M, Davidkin I, Virtanen M, et al. (1998) Explosive school-based measles outbreak: intense exposure may have resulted in high risk, even among revaccinees. Am J Epidemiol 148: 1103-1110.

4. Helfand RF, Kim DK, Gary HE Jr, Edwards GL, Bisson GP, et al. (1998) Nonclassic measles infections in an immune population exposed to measles during a college bus trip. J Med Virol 56: 337-341.

5. Ong G, Rasidah N, Wan S, Cutter J (2007) Outbreak of measles in primary school students with high first dose MMR vaccination coverage. Singapore Med J 48: 656-661.

6. Cisse B, Aaby P, Simondon F, Samb B, Soumaré M, et al. (1999) Role of schools in the transmission of measles in rural Senegal: implications for measles control in developing countries. Am J Epidemiol 149: 295-301.

7. Morita Y, Suzuki T, Shiono M, Shiobara M, Saitoh M, et al. (2007) Sequence and phylogenetic analysis of the nucleoprotein $(\mathrm{N})$ gene in measles viruses prevalent in Gunma, Japan, in 2007. Jpn J Infect Dis 60: 402-404.

8. Oliveira SA, Camacho LA, Pereira AC, Setúbal S, Nogueira RM, et al (2006) Assessment of the performance of a definition of a suspected measles case: implications for measles surveillance. Rev Panam Salud Publica 19: 229-235.

9. van Binnendijk RS, van den $\mathrm{Hof} S$, van den Kerkhof $\mathrm{H}$, Kohl $\mathrm{RH}$, Woonink $\mathrm{F}$ et al. (2003) Evaluation of serological and virological tests in the diagnosis of clinical and subclinical measles virus infections during an outbreak of measles in The Netherlands. J Infect Dis 188: 898-903.

10. Hasegawa T, Asaeda A, Hamaguchi Y, Numazaki K (2009) Development of rapid diagnostic reagents for measles. Hybridoma (Larchmt) 28: 241-249.

11. Numazaki K (2012) A study on the clinical application of a rapid diagnostic reagent for measles. Eur J Gen Med 9. 39-44.

12. World Health Organization (2007) Manual for the laboratory diagnosis of measles and rubella virus infection, 2nd, Geneva.

13. el Mubarak HS, Van De Bildt MW, Mustafa OA, Vos HW, Mukhtar MM, et al. (2000) Serological and virological characterization of clinically diagnosed cases of measles in suburban Khartoum. J Clin Microbiol 38: 987-991.

14. Ratnam S, Tipples G, Head C, Fauvel M, Fearon M, et al. (2000) Performance of indirect immunoglobulin $\mathrm{M}(\lg \mathrm{M})$ serology tests and $\operatorname{lgM}$ capture assays for laboratory diagnosis of measles. J Clin Microbiol 38: 99-104.

15. Tipples GA, Hamkar R, Mohktari-Azad T, Gray M, Parkyn G, et al. (2003) Assessment of immunoglobulin $\mathrm{M}$ enzyme immunoassays for diagnosis of measles. J Clin Microbiol 41: 4790-4792. 
Citation: Numazaki K (2015) Study on Assays for the Detection of Serum Antibodies to Measles from Children and Its Standardization. Int J Pediatr Neonat Care 1: 108. doi: http://dx.doi.org/10.15344/ijpnc/2015/108

Page 4 of 4

16. El Mubarak HS, Ibrahim SA, Vos HW, Mukhtar MM, Mustafa OA, et al (2004) Measles virus protein-specific IgM, IgA, and IgG subclass responses during the acute and convalescent phase of infection. J Med Virol 72: 290298.

17. Ono N, Tatsuo H, Hidaka $\mathrm{Y}$, Aoki T, Minagawa H, et al. (2001) Measles viruses on throat swabs from measles patients use signaling lymphocytic activation molecule (CDw150) but not CD46 as a cellular receptor. J Viro 75: 4399-4401.

18. Owens GP, Shearer AJ, Yu X, Ritchie AM, Keays KM, et al. (2006) Screening random peptide libraries with subacute sclerosing panencephalitis brainderived recombinant antibodies identifies multiple epitopes in the C-terminal region of the measles virus nucleocapsid protein. J Virol 80: 12121-12130. 